Abenteurer als Helden der Literatur 
Horst Albert Glaser /

Sabine Kleine-Roßbach (Hrsg.)

\section{Abenteurer als Helden der Literatur}

oder: Wie wurden oder machten sich Schwindler, Spione, Kolonialisten oder Militärs zu großen Gestalten der europäischen Literatur ?

Verlag J. B. Metzler Stuttgart · Weimar 
Die Deutsche Bibliothek - CIP-Einheitsaufnahme

\author{
Abenteurer als Helden der Literatur: \\ oder: Wie wurden oder machten sich Schwindler, Spione, Kolonialisten \\ oder Militärs zu großen Gestalten der europäischen Literatur? I \\ Horst Albert Glaser/Sabine Kleine-Roßbach (Hrsg.) \\ - Stuttgart ; Weimar : Metzler, 2002 \\ (M-\&-P-Schriftenreihe für Wissenschaft und Forschung) \\ ISBN 978-3-476-45301-3 \\ ISBN 978-3-476-02877-8 (eBook) \\ DOI 10.1007/978-3-476-02877-8
}

Dieses Werk einschließlich aller seiner Teile ist urheberrechtlich geschützt. Jede Verwertung außerhalb der engen Grenzen des Urheberrechtsgesetzes ist ohne Zustimmung des Verlages unzulässig und strafbar. Das gilt insbesondere für Vervielfältigungen, Übersetzungen, Mikroverfilmungen und die Einspeicherung und Verarbeitung in elektronischen Systemen.

M \& P Schriftenreihe für Wissenschaft und Forschung

(C) 2002 Springer-Verlag GmbH Deutschland

Ursprünglich erschienen bei J.B.Metzlersche Verlagsbuchhandlung und Carl Ernst Poeschel Verlag GmbH in Stuttgart 2002

www.metzlerverlag.de

Info@metzlerverlag.de 


\section{Inhalt}

Michael Naumann

Zum Geleit

Sabine Kleine-Roßbach

Einleitung

Bernhard Kytzler

Ein Helden- und ein Hundeleben. Christopher Columbus

Jan-Henrik Witthaus

Die Eroberung Mexikos. Hernán Cortés

Karl Maurer

Das Ende einer abenteuerlichen Existenz. Don Juan de Tassis y Peralta

Ralph-Rainer Wuthenow

Der Künstler als Abenteurer. Benvenuto Cellini

Sophie Linon-Chipon

La rupture à l'envers. Les frères Parmentier, Souchu de Rennefort, François Leguat

Gertrud Lehnert

Proben in erotischer Ambivalenz. Mademoiselle (de) Maupin

Horst Albert Glaser

Thronprätendent in Kurland. Maurice de Saxe

Joseph Gomsu

Auf der Suche nach dem Neuen Cythera. Georg Forster

Carola Hilmes

Aufbruch in den Orient. Lady Montagu, Lady Craven, 
Alexandre Stroev

„De la Russie, n’en croyez rien“. La fausse princesse de Brunswick

Günter Dammann

Ein König der Korsen. Theodor von Neuhoff

Horst Albert Glaser

„Le beau moment de partir“. Giacomo Casanova

Sabine Kleine-Roßbach

Larven - Rollen - Staffagen. Cagliostro

Angels Santa

Partir, fuir, voyager. Cagliostro

Volker Kapp

Vom kaiserlichen Librettisten zum New Yorker Buchhändler.

Lorenzo Da Ponte

Monika Schmitz-Emans

Der Abenteurer als Magnetiseur. Franz Anton Mesmer

Claude Foucart

Les „Isles de Bonheur“. François-René de Chateaubriand

Loïc Pierre Guyon

Un aventurier picaresque au XIXe siècle. Eugène-François Vidocq

Alan Corkhill

Reiseabenteuer in Australien. Friedrich Gerstäcker

Nina Ohligschläger

Als Taliban durch die Wüste. Isabelle Eberhardt

Michael Asher

An uncrowned King of Arabia? T.E. Lawrence 


\section{Zum Geleit}

Gleichförmig flossen Euphrat und Tigris dahin, gleichförmig verlief das Leben der Sumerer, der Assyrer, der Babylonier, regelmäßig stiegen die Flüsse einmal im Jahr über die Ufer, in jahrhundertewährender Stetigkeit fuhren die Bauern ihre Ernten ein, nichts änderte sich, auch nicht unter dem Ansturm der Eroberer - außer der Sprache: Die heroischen Gründungsmythen Mesopotamiens aber blieben gleich, die halbgöttlichen Gründungshelden verharrten in ihren schriftgewordenen Rollen. In Keilschrift gemeißelt, auf Tontafeln verewigt Enuma Elish, die Geschichte des Gilgamesch. Von mesopotamischen Löwenjagden wissen wir, auch von kriegerischen Auseinandersetzungen - aber $<$ Abenteurer> waren jene mesopotamischen Zivilisationsstifter nicht, allenfalls fromme Nachfolger im Dienste einer <imitatio heroica>. Die wahren Helden waren die Götter: Ihnen nachzufolgen war das mythisch kompakte Gebot, nicht freie Willensentscheidung.

Und in Europa? Zur gleichen Zeit? Tausende von Jahren vor unserer Zeitrechnung? Wir wissen es nicht. Abenteuerlich, davon dürfen wir ausgehen, war das Leben im Kampf mit den fast mannshohen menschenfresserischen Wölfen, den Raubtieren, den Gefahren der Wildnis, der Unbill des Wetters, der Feindseligkeit fremder Stämme - wir Europäer sind alle Nachfahren jener wenigen tausend Menschen, deren ungesicherter Alltag, aus unserer Perspektive gesehen, ein ewiges, fruchtbares Abenteurer gewesen sein muß. 
Der Schritt vom klassischen Heldentum sakraler Herkunft zur individualistischen Abenteuerei, vom heroischen Mythos zur <adventure story> ist der Gegenstand Ihres Kongresses, an dem teilzuhaben mir leider verwehrt ist. Gerne hätte ich mich mit Ihnen unterhalten über die <differentia spezifica> zwischen politischem <heros> der französischen Revolution und dem freiberuflichen Abenteurer, den doch gleiche, heiße Unaussprechlichkeiten im Herzen auf Entdeckungsfahrten in den Pazifik, die Karibik geführt haben, während in Paris die Bastille gestürmt wurde.

Wie kommt es, so fragte im 19. Jahrhundert Kropotkin, daß aus einfachen, biederen Ehemännern, aus Kommerzienräten und Notaren auf einmal revolutionäre Helden werden? Woher stammt der zündende Funke in ihren Seelen, der sie aus dem geregelten Alltag aufbrechen läßt in eine ungesicherte Zukunft voller Gefahren, voller Aventuren, ohne feste Ziele? Und wie kommt es, daß die Sozialtheoretiker des 19. Jahrhunderts im Proletariat über Nacht einen heroischen Charakter entdecken, ihm herkuleische Kräfte zuschreiben, ins Abenteuer der Weltrevolution gar schicken wollten - ohne selbst das Risiko der umstürzlerischen Tat jenseits des Schreibtischs, jenseits der Leselampe im British Museum zu suchen? Gab es Schreibtisch-Helden vor SchreibtischTätern?

Was treibt die Philosophen, mit Hegel das hohe Lied der Neuen Zeit zu singen, wie es das Motto Ihrer Konferenz zeigt, ,ein Loch in die Ordnung der Dinge hineinzustoßen, die Welt zu verändern, zu verbessern oder ihr zum Trotz wenigstens einen Himmel auf Erden herauszuschneiden“?

Wenn es das Abenteuer der Weltverändenung um seiner selbst willen gegeben hat, so waren wir am Ende des 20. Jahrhunderts auch an der Grenze aller Abenteuer angekommen, da die große, finale Weltveränderung, der nukleare Krieg, nichts anderes dargestellt hätte, als eine absurde Konsequenz jener Tapferkeit, die mit dem Gewehr, wieder mit Hegel gesprochen, abstrakt geworden war.

Und heute, wo liegen noch die Abenteuer? Schwerlich ist ein Grußwort geeignet, die Antwort auf derlei Fragen zu geben. Die Literatur wird sie weiter suchen - in der Politik, so steht zu hoffen, liegt sie jedenfalls nicht mehr. 
Vielleicht bedarf es einer gewissen Altersweisheit, die Odo Marquard zweifellos bewegt hatte, als er dem letzten großen Abenteurer/Philosophen der Geschichte, Karl Marx, über die Vergangenheit zurief: „Es kommt nicht darauf an, die Welt zu verändern, sondern sie zu verschonen"?

Heroisch wird inzwischen das tapfere Bewahren, das schwierige Erinnern im alles mit sich reißenden Sturm der Moderne. Die Abenteuer der Gegenwart finden inzwischen im Kopf statt. Später dann - das Weltall?

Der Konferenz wünsche ich von Herzen gutes Gelingen.

Dr. Michael Naumann

Staatsminister beim Bundeskanzler Beauftragter der Bundesregierung für Angelegenheiten der Kultur und der Medien 